\title{
Capílul 12
}

\section{Elaboração de brotos de soja em conserva}

Giovana Maria Navarro de Mendonça

Ana Flávia de Oliveira

\author{
Marcelo Álvares De Oliveira \\ Alexandre Rodrigo Coelho
}

\section{Introdução}

Estudos sobre a relação entre o consumo de soja e os benefícios à saúde humana vêm aumentando, devido às suas características nutricionais, ao elevado teor de proteínas, ou mesmo à grande quantidade de minerais e fibras, além da baixa quantidade de gordura saturada e a ausência de colesterol (SILVA et al., 2006). A composição da semente de soja é distribuída da seguinte forma: $40 \%$ proteína, 35\% de carboidratos, 20\% de ácidos graxos e 5\% de cinzas (LIU, 1997). Além disso, ela é fonte de ferro, cálcio, zinco, antioxidantes, vitamina E e outras vitaminas lipossolúveis (CARRÃO-PANIZZI; BORDIGNON, 2000).

$\mathrm{Na}$ safra de 2015/16, segundo a Companhia Nacional de Abastecimento (CONAB), a produção de soja no Brasil foi de 95.434,6 mil toneladas. O Paraná se destacou como o segundo maior produtor nacional, com uma produção de 16.844,5 mil toneladas, perdendo apenas para o estado do Mato Grosso, que produziu 26.030,7 mil toneladas (CONAB, 2017). Este crescimento se deve à aplicação de novas tecnologias, ao manejo e ao maior preparo dos produtores, propiciando aumento do cenário comercial interno do país nos últimos anos, uma vez que o seu consumo está sendo inserido cada vez mais na alimentação humana, além de o produto já ser utilizado na fabricação de rações animais.

Pesquisas realizadas por meio de parcerias, por exemplo, a Empresa Brasileira de Pesquisa Agropecuária (EMBRAPA) e seus parceiros, vêm contribuindo para o aumento da produção de soja, além de possibilitar a expansão do seu cultivo por regiões não anteriormente exploradas.

No caso da soja, existem genótipos específicos de soja em função da utilização dos seus grãos. Deste modo, a classificação da soja pode ser feita em dois grupos 
principais: soja tipo grão e soja tipo alimento. A soja tipo grão apresenta sementes de tamanhos médios, representados pelo peso de 100 sementes (PCS) entre 12 e 19 gramas, com seu sabor característico não muito agradável ao paladar humano, quando consumido na alimentação humana direta, sendo esta cultivada principalmente para atender às indústrias de farelo e óleo. A soja tipo alimento, com sabor mais suave e agradável ao paladar humano, apresenta duas categorias: sementes grandes, com PCS igual ou maior que 20 gramas, muito utilizada como soja hortaliça; e sementes pequenas, com PCS menor que 10 gramas, destinadas ao consumo na forma de brotos e de "natto" (YOKOMIZO; DUARTE; VELLO, 2000).

Uma proposta interessante seria a comercialização de brotos de soja, que são altamente nutritivos e cultivados sem qualquer tipo de adubo ou defensivo, que utilizam apenas as reservas armazenadas nas sementes para germinar. Os brotos são ricos em minerais, vitaminas e proteínas e apresentam baixa caloria ( 81 kcal), entretanto, para que os brotos possam se fixar num mercado consumidor, são necessárias tecnologias que possam garantir a produção em larga escala de sementes de soja apropriadas (OLIVEIRA et al., 2013).

A produção de sementes germinadas, como feijão moyashi e broto de soja, é uma atividade tradicional nos países orientais, que buscam sempre alternativas saudáveis e funcionais para introduzir em sua alimentação. No Brasil, esses produtos possuem um mercado ainda muito restrito, mas com um enorme potencial de crescimento. Este tipo de alimento poderia ser incentivado por meio da difusão de informações acerca das cultivares de soja (Glycine max (L) Merril) mais adequadas para a produção de brotos, como é o caso da semente pequena (PCS < $10 \mathrm{~g}$ ), bem como das tecnologias do processo que possibilitem produzir em larga escala e garantir a segurança do produto.

A cultivar BRS 216 desenvolvida pela Embrapa possui 10,4 g de peso médio de 100 sementes, semente pequena, com alto teor de proteína (em torno de 43\%) e com uma baixa produtividade quando comparada com as cultivares comerciais atuais do mercado, entretanto, é a única cultivar no mercado brasileiro que pode ser destinada à produção de brotos devido às características citadas anteriormente (EMBRAPA, 2005). Este trabalho teve por objetivo avaliar a qualidade físico-química, microbiológica e a aceitação sensorial de brotos de soja em conserva produzidos a partir dessa cultivar.

\section{Soja}

O surgimento da soja foi registrado há cerca de 5.000 anos na China, onde ela era considerada um dos cinco grãos sagrados. No Japão, a soja surgiu por volta de 200 a 300 anos antes de Cristo; na Europa, em 1740, e, no ano de 1804, ela apareceu nos Estados Unidos (LIU, 1997). 
A soja (Glycine Max (L.) Merril) é da família das leguminosas; é um produto de importância agrícola mundial, sendo um grão que apresenta grande versatilidade na sua utilização, podendo ser usada tanto na alimentação humana quanto na animal. Nota-se que a cada ano a produção de soja vem aumentando. O Brasil é o segundo maior produtor de soja do mundo, sendo a leguminosa mais cultivada em várias regiões do país (EMBRAPA, 2017; SILVA et al., 2006).

Como mencionado, existe uma ampla investigação sobre a relação entre o consumo de soja e a saúde humana por suas características nutricionais: seu elevado teor de proteínas, seu conteúdo significativo de fibras e minerais e por possuir uma quantidade baixa de gordura saturada e a ausência de colesterol (GRIESHOP; FAHEY, 2001).

\subsection{Soja no Brasil}

Por volta de 1882, houve um dos primeiros registros de soja do país, no estado da Bahia; em 1891, São Paulo e Rio Grande do Sul registraram seu cultivo. Com a chegada dos imigrantes japoneses em 1908, o plantio de soja foi aos poucos de difundindo e, em 1920, a soja chegou a Minas Gerais; em Santa Catarina, ela surgiu na década de 1930, e, em 1950, chegou a Goiás. Já nas regiões Norte, Nordeste e Centro-Oeste, a soja apareceu por volta da década de 1970 (MIYASAKA; MEDINA, 1981).

O Brasil foi o segundo maior produtor de soja do mundo, ficando atrás apenas dos Estados Unidos, na safra 2015/2016 (EMBRAPA, 2017). Na safra de 2015/16, a produção de soja no Brasil foi de 95.434,6 mil toneladas, sendo as regiões Centro-Oeste e Sul responsáveis por 48,5 e 34,0\% da produção, respectivamente, conforme apresentado na Tabela 1 (CONAB, 2017).

Tabela 1 - Produção de soja nas regiōes do Brasil

\begin{tabular}{lcc}
\hline Região/UF & $\mathbf{2 0 1 3 / 1 4}$ ( mil toneladas) & Porcentagem (\%) \\
\hline Norte & $3.818,90$ & 4,0 \\
Nordeste & $5.107,10$ & 5,4 \\
Centro-Oeste & $43.752,60$ & 45,9 \\
Sudeste & $7.574,90$ & 7,8 \\
Sul & $35.181,10$ & 36,9 \\
\hline Total & $95.434,60$ & 100 \\
\hline
\end{tabular}

Fonte: CONAB (2017). 
O Paraná se destacou como o segundo maior produtor nacional, com uma produção de 14.780,70 mil toneladas, perdendo apenas para o estado do Mato Grosso, que produziu 26.441,6 mil toneladas (Figura 1) (CONAB, 2017).

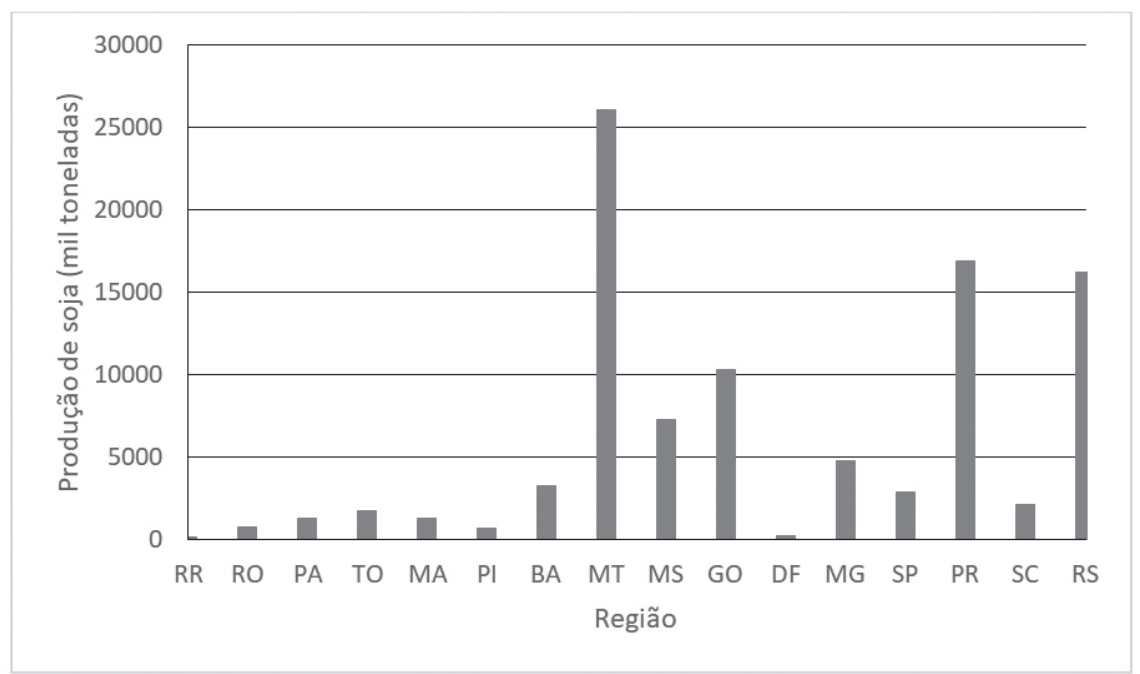

Figura 1 - Producãa de soja nos estados brasileiros, na safra 2015/16

Fonte: CONAB (2017)

\subsection{Características da soja e do broto}

A soja é considerada um alimento funcional, pois possui nutrientes essenciais ao organismo humano e que gera benefícios à saúde. Sua constituição é $90 \%$ de cotilédone, $8 \%$ de casca e $2 \%$ de hipocótilo (caule) (LIU, 1997).

Esta leguminosa rica em proteínas contém isoflavonas, saponinas, fitatos, inibidores de protease, fitosteróis, peptídeos com baixa massa molecular, oligossacarídeos e ácidos graxos poli-insaturados, que auxiliam na redução dos riscos de doenças crônicas e degenerativas. Possui também uma boa quantidade de minerais, ferro, potássio, magnésio, zinco, cobre, fósforo, manganês e vitaminas do complexo B (MANDARINO; CARRÃO-PANIZZI, 1998).

No entanto, a presença de fatores antinutricionais na soja faz com que nem todo seu valor nutricional seja utilizado, limitando o uso do grão; os inibidores das proteases, como a tripsina a quimotripsina e as hemaglutinas (que fazem as células vermelhas do sangue se aglutinarem, inibindo a absorção de oxigênio), prejudicam a digestão e podem chegar a $2 \%$ de seu conteúdo proteico, o que inviabiliza a utilização de suas proteínas pelo organismo dos monogástricos (SILVA; SILVA. 2000). 
Para a avaliação da eficiência do processamento térmico da soja, visando minimizar os fatores antinutricionais, existem muitos métodos, mas os que se destacam são os de índice de atividade ureática, a solubilidade da proteína em $\mathrm{KOH}$ e atividade inibitória de tripsina. O índice de atividade ureática é baseado no princípio que o calor desnatura a uréase e os inibidores de tripsina em mesma proporção (DALE; ARABA; WHITTLE, 1987).

O índice de atividade ureática é baseado na liberação de amônia da ureia pela ação da enzima uréase que está presente na soja; este fato causa a mudança de $\mathrm{pH}$ da solução que é demonstrado por meio do índice. A indústria americana de soja recomenda que o índice de atividade ureática seja de 0,05 a 0,20 $(\Delta \mathrm{pH})$ para fácil identificação dos extremos do processamento (DALE; ARABA; WHITTLE, 1987).

Da produção mundial de soja, $85 \%$ é processada para obtenção farelo de soja e óleo vegetal, sendo que a grande parte do farelo é utilizado na alimentação animal. Dos $15 \%$ restantes de soja, cerca de $10 \%$ é utilizado para a alimentação humana, e os $5 \%$ restantes são utilizados como sementes, ração animal ou são descartados (RIAZ, 2006).

A produção de bebidas (EHS - extrato hidrossolúvel de soja) vem sendo um destaque em relação ao consumo da soja, pois além da enorme quantidade de marcas encontradas em supermercados, esta também pode ser utilizada na elaboração de sorvetes e produtos similares ao leite condensado e creme de leite (GUERREIRO, 2006; RODRIGUES, 2003).

A germinação dos grãos de soja tem se mostrado um método muito efetivo e viável para que ocorra a melhora das qualidades desta leguminosa. Isso ocorre por conta de sua digestibilidade e eficiência proteica, aumentando deste modo suas vitaminas, e sua maior biodisponibilidade de minerais (FERNANDEZ-OROZCO et al., 2008).

Broto é qualquer semente que entre em contato com água, calor e ar, e deste contato resulte seu crescimento. Enquanto as sementes vão germinando, sua quantidade de clorofila vai aumentando, dando origem às folhas e ao caule. $\mathrm{O}$ broto germina de modo muito rápido (máximo sete dias), não depende da época do ano, não precisa de luz solar e de solo (LOURES, 2007; VIEIRA; LOPES, 2001).

Os brotos possuem um alto valor nutritivo, e sua produção não necessita de adubo específico ou defensivo. Por isso, são alimentos orgânicos, que utilizam suas próprias reservas armazenadas nas sementes para sua germinação e manutenção até o tamanho adequado para serem consumidos (OLIVEIRA et al., 2013). O feijão-mungo é a espécie mais conhecida quando se fala em brotos, mas existem mais de 30 espécies, destacando-se as olerícolas (brócolis, rabanete, cebola, mostarda, entre outros) e as leguminosas (feijão moyashi, alfafa, trevo, lentilha) (VEIRA; LOPES, 2001).

Os brotos são consumidos, em grande parte, em países como Japão, Estados Unidos e China. No Brasil, existe uma demanda crescente por este produto, e, 
entre as principais espécies que podem ser utilizadas para a produção de brotos, destacam-se: agrião (Lepidium sativum L.), alfafa (Medicago sativa L.), lentilha (Lens culinaris L.), feijão-mungo (Vigna radiata L.), ervilha (Pisum sativum L.), soja (Glycine max (L.) Merril) (KUO et al., 2004).

\subsection{Conservação por adição de ácidos}

Os alimentos são conservados desde a antiguidade a partir da acidificação, cujos ácidos podem atuar como inibidores de crescimento microbiano e/ou germinação de esporos, bem como na melhoria do sabor do produto (GARDNER, 1972).

$\mathrm{O}$ alimento acidificado geralmente apresenta $\mathrm{pH} \leq 4,6$, o que de certa forma auxilia no prolongamento da vida de prateleira do produto, uma vez que a variedade de micro-organismos que se desenvolvem nessas condições restringe-se a fungos e algumas bactérias (SANTANA et al., 1996; FRANCO; LANDGRAF, 2008).

\section{4 Ácido ascórbico}

O ácido ascórbico é um antioxidante utilizado para evitar o escurecimento e outras reações oxidativas em frutos, hortaliças e seus sucos. Ele é totalmente seguro para o consumo, e é capaz de aumentar o teor de vitamina $\mathrm{C}$ de algumas hortaliças e frutos, sendo bem aceito para o consumo por ser um composto químico idêntico à vitamina C (PRÉSTAMO; MANZANO, 1993; WILEY, 1994).

O ácido ascórbico, mais comumente conhecido como vitamina C, é encontrado em frutas e hortaliças; é estável em temperaturas baixas, mas é modificado quando ocorre alterações no oxigênio, luz, $\mathrm{pH}$, enzimas e catalisadores metálicos, bem como é degradado lentamente quando se encontra em ambiente de anaerobiose e atividade de água muita baixa (ORDÓÑEZ et al., 2005).

O ácido ascórbico é um sólido branco ou amarelo, seu ponto de fusão é de $190{ }^{\circ} \mathrm{C}$ a $192{ }^{\circ} \mathrm{C}$, sua massa molecular é $176,13 \mathrm{~g} / \mathrm{mol}$, densidade $1,65 \mathrm{~g} / \mathrm{cm}^{3}$, aci$\operatorname{dez}(\mathrm{pKa}):$ 4,17 (primeira), 11,6 (segunda), é solúvel em etanol absoluto, solúvel em água, insolúvel em solventes orgânicos comuns (benzeno, éter e clorofórmio) (BOBBIO; BOBBIO, 1995).

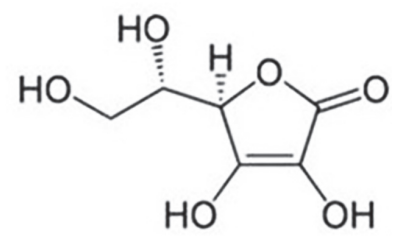

Figura 2 - Fórmula química do ácido ascórbico $\mathrm{C} 6 \mathrm{H} 806$ 


\subsection{Análise sensorial}

A análise sensorial de alimentos tem como finalidade caracterizar as qualidades sensoriais do produto, onde atributos como sabor, aparência e textura são de extrema importância. Ela atua desde a criação de um novo produto alimentício até a sua padronização e avaliação do nível de qualidade do produto, não se esquecendo das ferramentas analíticas que obedecem a alguns princípios básicos, como por exemplo, análises qualitativas, quantitativas e microbiológicas (DUTCOSKY, 2007).

Os métodos afetivos, no que diz respeito à aceitabilidade, podem ser definidos como uma experiência positiva e/ou consumo do produto. Os testes afetivos se baseiam na definição do público-alvo, onde são classificados por faixa etária, localização geográfica, sexo, classe social ou cultural, fatores étnicos e frequência de consumo. Sua classificação também pode ser dada por meio de testes qualitativos e quantitativos (DUTCOSKY, 2007).

O teste de aceitação tem como objetivo avaliar se os consumidores gostam ou não do produto. Estes padrões podem variar de pessoa para pessoa, levando-se em consideração a base cultural, o padrão de vida, capacidade de reagir ao preço do produto etc. Dentre as escalas hedônicas, aquela classificada como verbal é utilizada quando se pretende trabalhar com ideias de ordem sucessiva, enquanto 2as escalas faciais são empregadas quando o público é infantil ou não sabe ler. Por outro lado, a escala hedônica não estruturada é caracterizada por uma linha horizontal, que varia de um extremo contendo a expressão "desgostei extremamente" até o outro extremo com a expressão "gostei extremamente” (MINIM, 2006).

\section{Material e métodos}

Trata-se de uma pesquisa experimental que objetivou avaliar brotos de soja em salmoura, com análises quantitativas e qualitativas deste produto depois de pronto, sendo elas físico-químicas e microbiológicas em quatro tempos estabelecidos: tempo um, dois, quatro e seis meses de armazenamento. As análises físicoquímicas e sensorial foram realizadas na Embrapa Soja em Londrina e as análises microbiológicas foram realizadas no laboratório de microbiologia da Universidade Tecnológica Federal do Paraná, campus Londrina, no período de novembro de 2014 a junho de 2015.

\subsection{Material em estudo}

As sementes de soja da cultivar BRS 216 foram fornecidas pela Embrapa Serviço de Negócios Tecnológicos (SNT) e Fundação Meridional de Apoio e Pesquisa 
Agropecuária - Londrina, PR, e os ingredientes utilizados para o preparo da salmoura para a conserva do produto também foram fornecidos pela Embrapa Soja.

\subsection{Métodos}

Os métodos utilizados para o preparo das sementes, como seleção, armazenamento, preparo da salmoura, produção dos brotos e as análises realizadas ao longo de seu tempo de armazenamento estão descritas conforme metodologia específica para cada parâmetro analisado, e todo o seu processo de produção descrita a seguir.

\subsubsection{Preparo da salmoura}

A salmoura utilizada neste estudo foi formulada na concentração de $25 \mathrm{~g} / \mathrm{L}$ de $\mathrm{NaCl}$ e 5 g/L de ácido ascórbico.

\subsubsection{Seleção e preparo das sementes}

A soja utilizada foi a BRS 216, desenvolvida pela Embrapa Soja, cujos grãos possuem um tamanho pequeno (aproximadamente 10,4 $\mathrm{g}$ em peso médio de 100 sementes). Aproximadamente 1,5 $\mathrm{kg}$ de sementes foi submetido a uma limpeza na qual as sujidades foram manualmente retiradas. As sementes selecionadas foram acondicionadas em saco plástico transparente e armazenadas em câmara seca a $15^{\circ} \mathrm{C}$, no Laboratório de Tecnologia de Sementes, até o momento de sua utilização.

Em seguida, as sementes foram higienizadas por imersão em solução de hipoclorito de sódio $10 \%$ por 4 minutos, seguido de enxágue e maceração por quatro horas em temperatura ambiente em um recipiente contendo água clorada. Ao final deste período, procedeu-se o escorrimento da água e as sementes foram designadas para a germinação e produção dos brotos.

\subsubsection{Produção dos brotos}

As sementes de soja previamente maceradas e drenadas foram colocadas em tanques de germinação, que consistiram de caixas d'água com capacidade de 100 litros, contendo peneiras de inox no interior, para dar sustentação às sementes e possibilitar a germinação dos brotos. As sementes foram irrigadas durante quatro dias (a cada 4 horas por 1 minuto) com água potável para promover a germinação dos brotos. Ao longo deste período, a água era drenada do tanque por meio de um ralo. O processo de germinação foi controlado com o auxílio de um 
"timer", que condicionava o tempo e a duração da irrigação, de forma que todo o processo fosse uniforme.

\subsubsection{Conserva}

Após o período de quatro dias, os brotos foram removidos manualmente das peneiras de aço inox, pesados em quantidades de aproximadamente $50 \mathrm{~g}$ e acondicionados em frascos de vidro de $375 \mathrm{~mL}$ e com tampa metálica do tipo "twist off" (previamente sanitizados), seguido de adição de cerca de $300 \mathrm{~mL}$ da salmoura. Em seguida os frascos foram fechados e submetidos ao processo de pasteurização em banho-maria $\left(85^{\circ} \mathrm{C}\right.$ por 30 minutos), sendo então completamente vedados e estocados em prateleira com luz solar incidente na sala, porém não sobre os frascos, por um período de 180 dias.

\subsubsection{Análises físico-químicas}

As análises físico-químicas das amostras de brotos de soja em conserva consistiram na determinação do $\mathrm{pH}$, sólidos solúveis (realizadas em triplicata) e índice de atividade ureática (feito na semente e no broto). As análises foram realizadas no tempo um (produto recém-produzido), e após dois, quatro e seis meses de estocagem.

\subsubsection{Determinação do pH}

Para a determinação do $\mathrm{pH}$, foram utilizados $10 \mathrm{~g}$ da amostra, que foi macerada com o auxílio de um graal e pistilo, e transferida para um béquer contendo $100 \mathrm{~mL}$ de água destilada, conforme metodologia descrita pelo Instituto Adolfo Lutz (1985). A análise foi realizada em triplicata. O potenciômetro foi previamente calibrado com as soluções tampões de $\mathrm{pH}$ 7,0 e 4,0.

\subsubsection{Determinação de sólidos solúveis por refratometria}

Foram macerados $5 \mathrm{~g}$ da amostra em graal e transferidos para uma gaze. Uma alíquota foi retirada e transferida para o refratômetro tipo Abbé, e a leitura realizada em ${ }^{\circ}$ BRIX. A análise foi realizada em triplicata.

\subsubsection{3 Índice de atividade ureática}

Um volume de 0,2 g de amostra foi transferido para um tubo de ensaio (A), e adicionado de $10 \mathrm{~mL}$ de solução tampão $\mathrm{pH}$ 7,0, seguido de leve agitação. O tubo 
foi tampado e colocado em banho-maria a $30{ }^{\circ} \mathrm{C}$, anotando assim o tempo em que o mesmo foi incubado, para considerá-lo como prova em branco (PB).

Pesou-se 0,2 g da amostra (B) conforme mencionado acima, seguido de adição de $10 \mathrm{~mL}$ de solução de ureia tamponada pH 7,0. O tubo de ensaio foi tampado e colocado em banho-maria a $30{ }^{\circ} \mathrm{C}$, seguido de anotação do tempo de incubação, para considerá-lo como prova teste (PD).

Ambos os tubos (A e B) foram retirados do banho-maria após 30 minutos de permanência, foi decantado o líquido sobrenadante em um recipiente (béquer) e medido o $\Delta \mathrm{pH}$ da solução branco e teste (A.O.A.C. 1995).

\subsubsection{Análises microbiológicas}

As análises microbiológicas consistiram na Determinação do Número Mais Provável-NMP de coliformes a $45^{\circ} \mathrm{C}$, contagem de Staphylococcus coagulase positiva e pesquisa de Salmonella sp., conforme estabelecido pela Resolução (RDC) 12/2001 da Agência Nacional de Vigilância Sanitária (BRASIL, 2001).

\subsubsection{Preparo das amostras para análise}

Para o preparo da amostra, pesou-se assepticamente 25 gramas do produto (previamente homogeneizado) e transferiu-se para um Erlenmeyer contendo 225 $\mathrm{mL}$ de água peptonada estéril $0,1 \%$ como diluente. A partir desta diluição $\left(10^{-1}\right)$, foram realizadas diluições decimais seriadas até $10^{-3}$, sendo então utilizadas para a Determinação do NMP de coliformes a $45^{\circ} \mathrm{C}$ e a contagem de Staphylococcuscoagulase positiva.

As análises de coliformes e de Staphylococcus coagulase positiva foram realizadas conforme metodologia preconizada pela American Public Health Association - APHA (2001) descritas por Silva et al. (2007), enquanto a pesquisa de Salmonella sp. seguiu metodologia da International Organization for Standardization (ISO, 2007).

\subsubsection{Número mais provável - NMP de coliformes a $45^{\circ} \mathrm{C}$}

Para esta análise, utilizou-se a técnica de tubos múltiplos, empregando-se três séries de três tubos, contendo Caldo Lauril Sulfato Triptose - LST e tubo de Durhan, seguido de incubação a $35^{\circ} \mathrm{C} / 48 \mathrm{~h}$.

A partir dos tubos que apresentaram turvação e formação de gás no interior dos tubos de Durhan, transferiu-se uma alíquota $(1 \mathrm{~mL})$ para tubos de ensaio contendo Caldo Bile Verde Brilhante 2\% - VB (confirmação de coliformes a 35 
${ }^{\circ} \mathrm{C}$ ) e $1 \mathrm{~mL}$ para tubos de ensaio contendo Caldo Escherichia coli - EC (usado para confirmação de coliformes a $45^{\circ} \mathrm{C}$ ), seguidos de incubação a $35^{\circ} \mathrm{C} / 24-48$ h e $44,5{ }^{\circ} \mathrm{C} / 24 \mathrm{~h}$, respectivamente. O NMP/g do produto foi determinado com auxílio da tabela de Hoskings (SILVA et al., 2007).

\subsubsection{Contagem de estafilococos coagulase positiva}

Nesta análise utilizou-se o método de semeadura por superfície, inoculandose $0,1 \mathrm{~mL}$ das diluições em placas de Petri contendo Ágar Baird Parker com solução de gema de ovo e telurito de potássio $1 \%$. As placas foram incubadas a $37^{\circ} \mathrm{C}$ por 48 horas e as colônias suspeitas (evidenciadas por coloração negra, brilhante, com halo transparente ao redor) foram submetidas ao teste de coagulase para confirmação. As Unidades Formadoras de Colônias - UFC foram calculadas de acordo com as diluições (SILVA et al., 2007).

\subsubsection{Pesquisa de Salmonella sp}

Em $225 \mathrm{~mL}$ de Caldo Lactosado foram adicionados $25 \mathrm{~g}$ de amostra. Após incubação a $37^{\circ} \mathrm{C}$ por 18 horas, $1 \mathrm{~mL}$ do pré-cultivo foi transferido para tubos de ensaio contendo $10 \mathrm{~mL}$ de Caldo Tetrationato de Kauffmann, e 0,1 mL foi transferido para tubos com $10 \mathrm{~mL}$ de Caldo Rappaport-Vassiliadis, seguido de incubação a $37^{\circ} \mathrm{C} / 24$ h e $41,5^{\circ} \mathrm{C} / 24 \mathrm{~h}$, respectivamente. Em seguida foram feitas semeaduras por esgotamento em placas de Petri contendo Ágar Xilose Lisina Desoxicolato (XLD) e Ágar Salmonella Shigella - SSA. As colônias suspeitas (vermelhas com centro negro em XLD e incolores, com ou sem centro negro em SSA) foram submetidas à prova de soroaglutinação, que se baseia na reação antígeno-anticorpo, com consequente aglutinação do antígeno frente ao antissoro para Salmonella polivalente “O” (ISO, 2007).

\subsubsection{Análise sensorial}

Avaliou-se a aceitação do broto de soja em conserva por meio de teste afetivo, com auxílio de uma escala hedônica de nove pontos, conforme a Tabela 2 (DUTCOSKY, 2007). Com base no resultado da média da aceitação geral do produto, realizou-se o Índice de Aceitabilidade e considerou-se $70 \%$ ou mais para que o produto seja considerado bem aceito (DUTCOSKY, 2007).

Participaram dessa análise 101 provadores; pesquisadores, estagiários e funcionários da EMBRAPA Soja, maiores de 18 anos, de ambos os sexos. Os candidatos foram convidados a participar do teste e, ao aceitarem, foram orientados a ler e assinar o termo de consentimento livre e esclarecido. 
O teste foi conduzido na cozinha experimental da EMBRAPA Soja, em cabines individuais, cuja amostra ofertada continha de 8 a 10 brotos de soja disposta em pratos plásticos. Os atributos avaliados foram aparência, sabor, textura, aceitação global e intenção de compra. Além disso, avaliou-se a idade do participante e seu consumo habitual de soja e seus derivados.

Tabela 2 - Escala hedônica

\section{Escala hedônica}

\begin{tabular}{ll}
$\mathbf{9}$ & gostei muitíssimo \\
$\mathbf{8}$ & gostei muito \\
$\mathbf{7}$ & gostei moderadamente \\
$\mathbf{6}$ & gostei ligeiramente \\
$\mathbf{5}$ & nem gostei/nem desgostei \\
$\mathbf{4}$ & desgostei ligeiramente \\
$\mathbf{3}$ & desgostei moderadamente \\
$\mathbf{2}$ & desgostei muito \\
$\mathbf{1}$ & desgostei muitíssimo \\
\hline
\end{tabular}

Fonte: Dutcosky (2007).

\section{Resultados e discussão}

Os resultados descritos abaixo mostram o comportamento do produto ao longo de seu tempo de armazenamento, por meio das análises de $\mathrm{pH}$, sólidos solúveis, índice de atividade ureática e análises microbiológicas, como também as respostas obtidas para a análise sensorial.

\subsection{Análises físico-químicas}

As análises foram realizadas no tempo 1 (produto recém-produzido), e após 2, 4 e 6 meses. Na Tabela 3 observa-se que os valores de $\mathrm{pH}$ obtidos variaram de 4,4 a 4,2. Estes valores mostram que o produto em estudo está de acordo com a Resolução RDC $n^{\circ} 272 / 05$, que define para uma conserva vegetal que os valores de $\mathrm{pH}$ devem ser inferiores a 4,5 (BRASIL, 2005).

Para a análise de sólidos solúveis ( ${ }^{\circ}$ BRIX), foi obtida a mesma média de 4,6 para os quatro tempos, com pequena variação apenas no desvio padrão. Por meio 
dos valores obtidos, nota-se que os brotos possuem uma quantidade de sólidos solúveis baixa, que não se altera ao longo do tempo de armazenagem.

Tabela 3 - Valores médios de pH e sólidos solúveis

\begin{tabular}{ccc}
\hline Tempo & $\mathbf{p H}$ & Sólidos solúveis (' ${ }^{\circ} \mathbf{R I X )}$ \\
\hline $\mathbf{1}$ & $4,4 \pm 0,0$ & $4,6 \pm 0,2$ \\
$\mathbf{2}$ & $4,2 \pm 0,0$ & $4,6 \pm 0,3$ \\
$\mathbf{4}$ & $4,2 \pm 0,0$ & $4,6 \pm 0,1$ \\
$\mathbf{6}$ & $4,2 \pm 0,0$ & $4,6 \pm 0,2$ \\
\hline
\end{tabular}

Fonte: Autoria própria.

A Tabela 4 demonstra que no broto de soja a uréase está inativa, pois não houve grande variação entre os pHs da amostra e da prova em branco, o que demonstra que a ureia da reação não foi consumida pela amostra. Segundo a Indústria Americana da Soja é recomendado índice de atividade ureática de 0,05 a 0,20 (BELLAVER; SNIZEK JUNIOR, 1999).

Na mesma Tabela 4, mas para o grão, a média do índice de atividade da uréase foi de 2,11. Segundo Butolo (2002), o grão cru apresenta índice de atividade ureática de 2,0 a 2,5.

Tabela 4 - Determinação do índice de atividade ureática nos brotos de soja em conserva

\begin{tabular}{ccc}
\hline \multirow{2}{*}{ Repetições } & \multicolumn{2}{c}{ atividade ureática $(\mathbf{\Delta} \mathbf{p H})^{*}$} \\
\cline { 2 - 3 } & Grão & Broto \\
\hline I & 2,11 & 0,04 \\
II & 2,10 & 0,05 \\
III & 2,12 & 0,05 \\
\hline
\end{tabular}

$* \Delta \mathrm{pH}=\mathrm{PD}-\mathrm{PBranco}$

Fonte: Autoria própria.

\subsection{Análises microbiológicas}

$\mathrm{Na}$ Tabela 5 estão apresentados os resultados das análises microbiológicas prescritas pela legislação brasileira, que estabelece os padrões microbiológicos sanitários para alimentos (BRASIL, 2001). Considerando-se a similaridade da 
natureza e do processamento do produto, o broto de soja em conserva foi enquadrado no grupo 4 (outros vegetais), item b do Anexo 1 da Resolução da Diretoria Colegiada número 12 - RDC 12, de 2 de janeiro de 2001, que descreve os padrões microbiológicas para vegetais em salmoura, temperados ou não, condimentados ou não, não comercialmente estéreis.

O produto foi submetido às análises microbiológicas ao longo dos seis meses de armazenamento, a fim de observar a efetividade do acondicionamento do produto nos frascos.

Tabela 5 - Avaliação da qualidade microbiológica de brotos em conserva

\begin{tabular}{clcc}
\hline Tempo (meses) & Salmonella sp & $\begin{array}{c}\text { Staphylococcus } \\
\text { coagulase positiva }\end{array}$ & $\begin{array}{c}\text { Coliformes a } \\
\mathbf{4 5}^{\circ} \mathbf{C}\end{array}$ \\
\hline $\mathbf{1}$ & ausência & $<10 \mathrm{UFC} / \mathrm{g}$ & $<3 \mathrm{NMP} / \mathrm{g}$ \\
$\mathbf{2}$ & ausência & $<10 \mathrm{UFC} / \mathrm{g}$ & $<3 \mathrm{NMP} / \mathrm{g}$ \\
$\mathbf{4}$ & ausência & $<10 \mathrm{UFC} / \mathrm{g}$ & $<3 \mathrm{NMP} / \mathrm{g}$ \\
$\mathbf{6}$ & ausência & $<10 \mathrm{UFC} / \mathrm{g} \mathrm{NMP} / \mathrm{g}$ \\
Padrão & Ausência em 25 gramas & $5 \times 10^{2} \mathrm{UFC} / \mathrm{g}$ & $1,0 \times 10^{2} \mathrm{NMP} / \mathrm{g}$ \\
\hline
\end{tabular}

Fonte: Autoria própria.

De acordo com os resultados obtidos, o produto apresentou-se de acordo com os padrões legais vigentes, ou seja, em condições sanitárias satisfatórias. Neste sentido, o produto elaborado estava apto para ser submetido ao teste de aceitação na análise sensorial.

Considerando que o produto apresentou valores de $\mathrm{pH}$ abaixo de 4,5, e, portanto, classificado como ácido, é possível sugerir que o mesmo se encontra seguro do ponto de vista microbiológico. Segundo Franco e Landgraf (2008), micro-organismos patogênicos necessitam de valores superiores a 4,5 para se desenvolver e produzir toxinas.

Na Figura 3-a observa-se o produto recém-produzido. Em valores muito baixos de pH, o crescimento microbiano limita-se aos bolores e leveduras, que são agentes responsáveis apenas pela deterioração de produtos com essa característica. O crescimento destes micro-organismos é evidenciado por turvação, formação de película ou sedimentação (FRANCO; LANDGRAF, 2008). Entretanto, conforme observado na Figura 3-b, a salmoura permaneceu límpida, clara e sem formação de qualquer película ou sedimentação no interior dos frascos ao longo 
do tempo de armazenamento, sugerindo que o processo de sanitização dos frascos e o branqueamento do produto foram realizados de forma adequada, comprovado pelas análises microbiológicas.

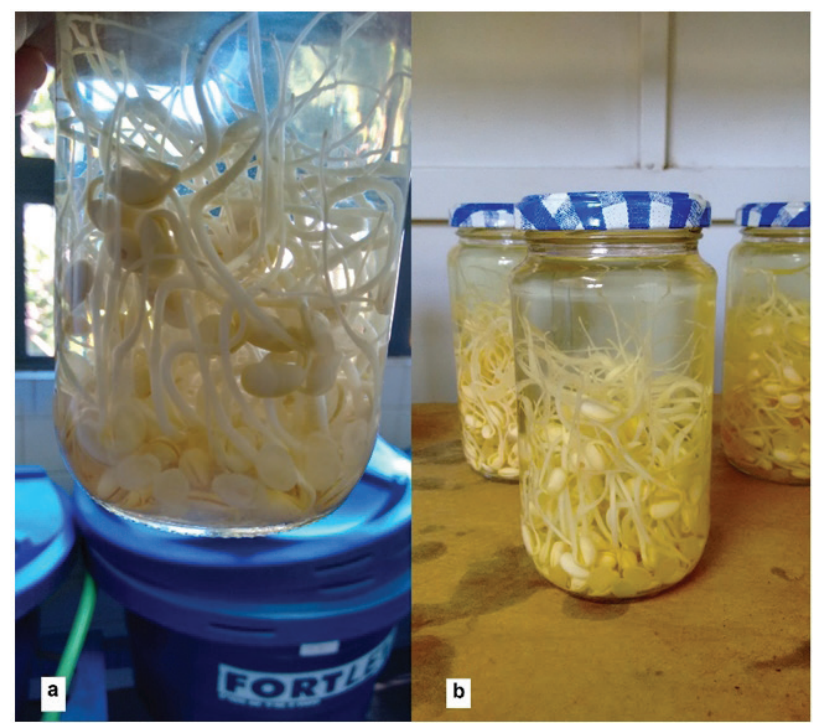

Figura 3 - Produto recém-produzido (a) e produto após 6 meses de armazenamento (b)

Fonte: Autoria própria

\subsection{Análise sensorial}

De acordo com os resultados obtidos por meio da análise sensorial, a aceitação do produto variou entre "gostei ligeiramente" e "gostei moderadamente", sendo as médias de cada atributo: aparência $6,9 \pm 1,6$; textura, $7,3 \pm 1,7$; sabor, $7,4 \pm 1,9$; e aceitação global do produto, 7,3 $\pm 1,7$. Vilas Boas, Barcelos e Lima (2012), utilizando-se também de uma escala hedônica de nove pontos, avaliaram degustação e aparência de brotos de soja sendo que, para a degustação, as notas variaram entre 6 e 7 e, para a aparência, de 4 a 6, de acordo com o tempo de germinação. Observa-se que a aceitação do broto de soja em conserva em nosso estudo foram maiores.

O índice de aceitabilidade do broto de soja em conserva foi de $76,7 \%$, ou seja, o produto pode ser considerado bem aceito sensorialmente. Oliveira et al. (2013) avaliaram a aceitação geral de broto de soja cozido e obtiveram índice de aceitabilidade muito parecido, de $74,3 \%$.

No Gráfico 1 pode-se verificar a frequência das respostas obtidas para cada um dos atributos estudados. Observa-se que a maioria dos resultados se encontra nas notas 7,8 e 9 . 
Gráfico 1 - Frequência de notas obtidas para aparência, textura, sabor e aceitação global dos brotos de soja.

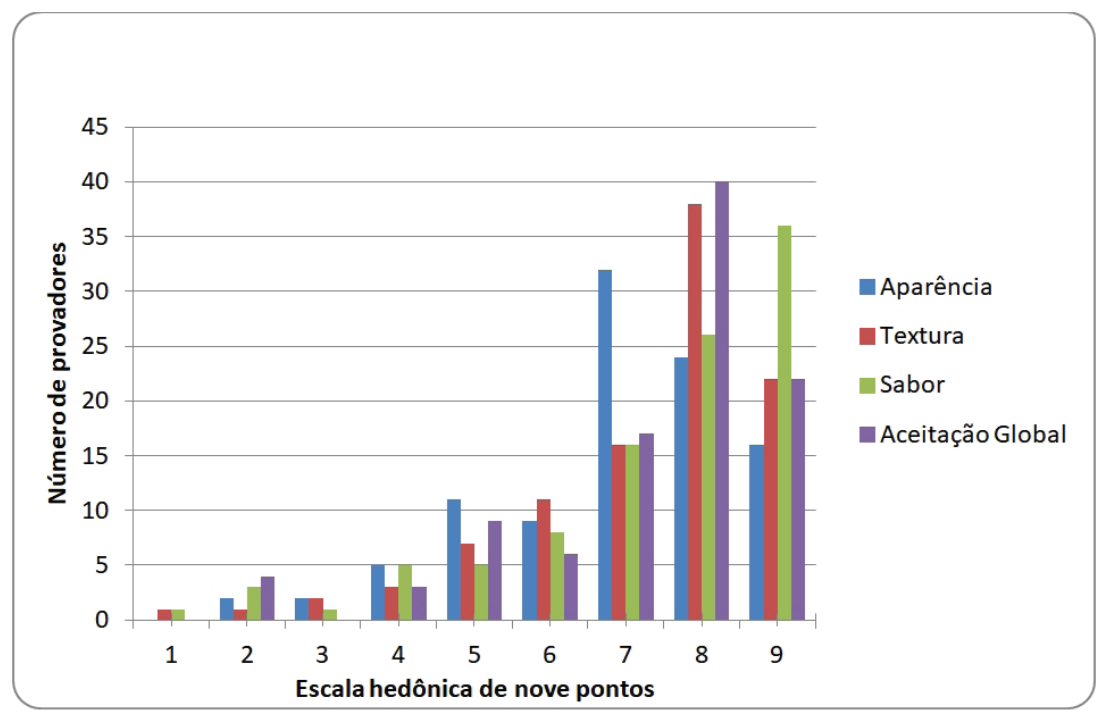

Fonte: Autoria própria.

O Gráfico 2 mostra a distribuição dos provadores por faixa etária, evidenciando que o grupo recrutado foi bastante diversificado e representativo do potencial público consumidor deste produto.

Gráfico 2 - Distribuicãa de provadores do broto de soja por faixa etária.

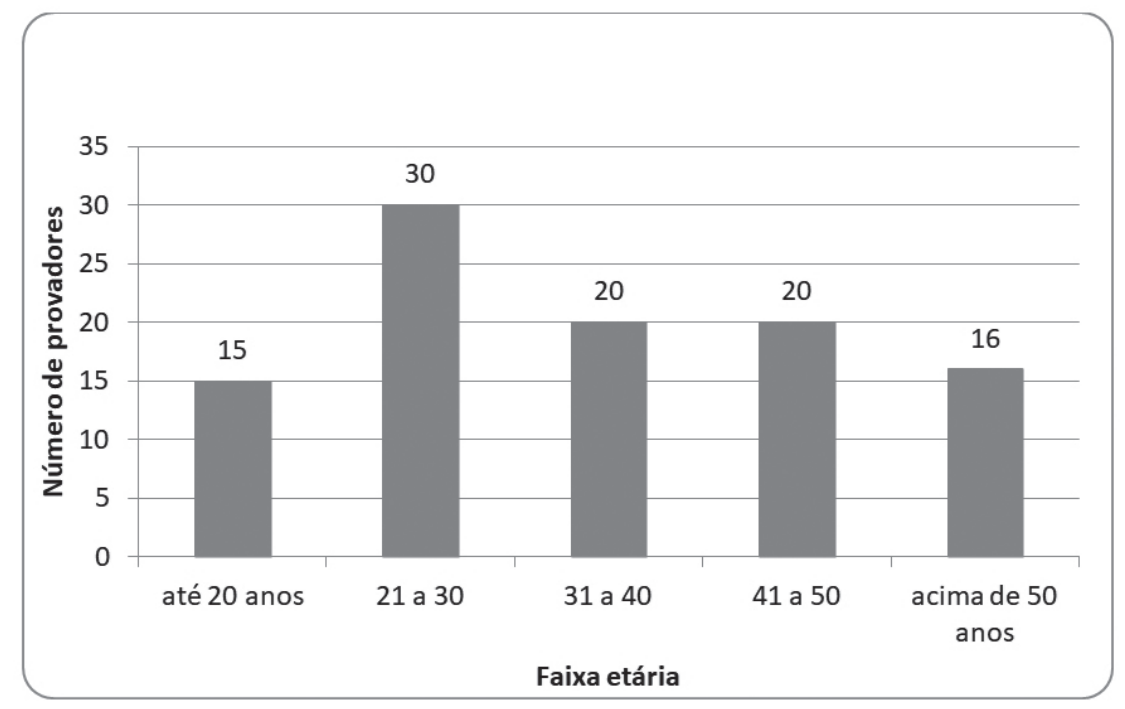

Fonte: Autoria própria. 
Quando perguntados se tinham o hábito de consumir brotos, 72\% dos provadores responderam afirmativamente. Sobre a intenção de compra, caso este produto fosse vendido em redes de supermercados, aproximadamente $87 \%$ dos provadores afirmaram que o comprariam, indicando, assim, um possível novo nicho de mercado, no entanto vale a pena ressaltar que não se avaliou o possível custo deste produto para tal afirmação.

\section{Conclusão}

As análises físico-químicas mostraram que o broto de soja em conserva não sofreu grande variação ao longo do tempo de armazenamento, bem como apresentou qualidade microbiológica de acordo com os padrões legais vigentes, ou seja, em condições sanitárias satisfatórias, portanto apto para o consumo humano. Além disso, o produto apresentou boa aceitação sensorial.

\section{Agradecimentos}

Os autores agradecem a Embrapa Soja - Londrina pela doação das sementes de soja e pela realização das análises físico-químicas do produto, bem como agradecem a UTFPR pelo auxílio financeiro para o desenvolvimento das análises microbiológicas e análise sensorial.

\section{Referências}

AMERICAN PUBLIC HEALTH ASSOCIATION (APHA). Compendium of methods for the microbiological examination of foods. 4. ed. Washington, DC: APHA, 2001.

ASSOCIATION OF OFFICIAL ANALYTICAL CHEMISTS (AOAC). Official Methods of Analysis. 12. ed. Washington, DC: AOAC, 1995.

BELLAVER, C.; SNIZEK JUNIOR, P. N. Processamento da soja e suas implicações na alimentação de suínos e aves. In: CONGRESSO BRASILEIRO DE SOJA, 1999, Londrina, PR. Anais... Londrina: Embrapa Soja, 1999.

BRASIL. Ministério da Saúde. Agência Nacional de Vigilância Sanitária. Resolução RDC n. 272, de 22 de setembro de 2005. Regulamento Técnico para Produtos de Vegetais, Produtos de Frutas e Cogumelos Comestíveis. Diário Oficial da União da República Federativa do Brasil. Brasília, 2005. Disponí- 
vel em: <http://www.puntofocal.gov.ar/notific_otros_miembros/bra168a1_t. pdf>. Acesso em: 15 jan. 2016.

. Ministério da Saúde. Agência Nacional de Vigilância Sanitária. Resolução RDC n. 12, de 2 de janeiro de 2001. Aprova o regulamento técnico sobre padrões microbiológicos para alimentos. Diário Oficial da União da República Federativa do Brasil. Brasília, 2001.

BOBBIO, F. O.; BOBBIO, P. A. Introdução à química de alimentos. 2. ed. São Paulo: Varela, 1995.

BUTOLO, J. E. Qualidade de ingredientes na alimentação animal. Colégio Brasileiro de Nutrição Animal, Campinas, p. 410-430, 2002.

CARRÃO-PANIZZI, M. C.; BORDINGNON, J. R. Activity of beta-glucosidase and levels of isoflavone glucosides in soybean cultivars affected by the environment. Pesquisa Agropecuária Brasileira, v. 35, n. 5, p. 873-878, 2000.

COMPANHIA NACIONAL DE ABASTECIMENTO - CONAB. Séries históricas de área plantada, produtividade e produção, relativas às safras 1976/77 a 2014/15 de grãos, 2001 a 2014 de café, 2005/06 a 2014/15 de cana-de-açúcar. Disponível em: <http://www.conab.gov.br/conteudos.php?a=1252\&ordem=produto\&Pagina_objcmsconteudos=3\#A_objcmsconteudos >. Acesso em: 10 fev. 2017.

DALE, N. M.; ARABA, M.; WHITTLE, E. Protein solubility as an indicator of optimum processing. In: 1987 Georgia Nutrition Conference for the Feed Industry. Atlanta, Georgia, 1987. p. 88-95

DUTCOSKY, S. D. Análise Sensorial de Alimentos. 2. ed. Curitiba: Champagnat, 2007.

EMBRAPA. Empresa Brasileira de Pesquisa Agropecuária. Cultivares de soja 2004/2005: Regiões Centro-Sul. Londrina: Embrapa Soja; Fundação Meridional, 2005.

Soja. Disponível em: <https://www.embrapa.br/soja/cultivos/soja1>. Acesso em: 10 jan. 2017.

FERNANDEZ-OROZCO, R. et al. Kinetic study of the antioxidant compounds and antioxidant capacity during germination of Vigna radiate cv. Emerald, 
Glycine max cv. Jutro and Glycine max cv. merit. Food Chemistry, n. 111, p. 622-631, 2008.

FIORUCCI, A. R. A importância da vitamina C na sociedade através dos tempos. Química Nova na Escola, São Paulo, v. 17, p. 3-10, 2003.

FRANCO, B. D. G. M.; LANDGRAF, M. Microbiologia dos alimentos. São Paulo: Atheneu, 2008.

GARDNER, W. H. Acidulants in food processing. In: FURIA, T. E. Handbook of Food Additives. 2. ed. Boca Raton: CRC Press, 1972.

GRIESHOP, C. M.; FAHEY JR., G. C. Comparison of quality characteristics of soybeans from Brazil, China, and the United States. J. Agric. Food Chem., v. 49, n. 5, p. 2669-2673, 2001.

GUERREIRO, L. Dossiê Técnico: produtos de soja. Rio de Janeiro: Rede de Tecnologia do Rio de Janeiro - REDETEC; Serviço Brasileiro de Respostas Técnicas - SBRT, 2006.

INSTITUTO ADOLFO LUTZ - IAL. Normas Analíticas do Instituto Adolfo Lutz: métodos químicos e físicos para análises de alimentos. Vol 1. 3. ed. Brasília: Ministério da Saúde, 1985.

THE INTERNATIONAL ORGANIZATION FOR STANDARDIZATION - ISO. ISO 6579. Microbiology of food and animal feeding stuffs - Horizontal method for the detection of Salmonella spp. 4. ed. Amendment 1: 15/07/2007.

KUO, Y-H. et al. Effects of different germination conditions on the contents of free protein and non-protein amino acids of commercial legumes. Food Chemistry, v. 86, p. 537-545, 2004.

LOURES, N. T. P. Caracterização físico-química, microbiológica e sensorial de brotos de lentilha de variedade Precoz. 2007. 67f. Dissertação (Mestrado em Engenharia Agrícola) - Universidade Estadual do Oeste do Paraná, Cascavel, PR.

LIU, K. Food use of whole soybeans. In: LAWRENCE, A. J.; WHITE, P. J.; GALLOWAY, R. Soybeans chemistry, production, processing, and utilization. Urbana: AOCS Press, 2008. p. 320-410. 
MANDARINO, J. M. G; CARRÃO-PANIZZI, M. C. Soja: saborosa, nutritiva e saudável. 1998. Disponível em: <http://ainfo.cnptia.embrapa.br/digital/bitstream/item/123013/1/ID-17096.pdf>. Acesso em: 16 mar. 2015.

MINIM, V. P. R. Análise sensorial: estudos com consumidores. Viçosa: Editora UFV, 2006.

MIYASAKA, S.; MEDINA, J. C. A soja no Brasil. Campinas: ITAL, 1981.

OLIVEIRA, M. A. et al. Produção de brotos de soja utilizando a cultivar BRS 216: caracterização físico-química e teste de aceitabilidade. Brazilian Journal of Food Technology, Campinas, v. 16, n. 1, p. 34-41, 2013.

PRÉSTAMO, G.; MANZANO, O. Peroxidases of selected fruits and vegetables and the possible use of ascorbic acid as an antioxidant. HortScience, Alexandria, v. 28, n. 1, p. 48-50, 1993.

RIAZ, M. N. Processing of soybeans into ingredients. In: Soy applications in food. Boca Raton: Taylor \& Francis, 2006. p. 39-62.

SANTANA, L. R. R. et. al. Desenvolvimento do processo de ovos de codorna em conserva. Salvador, 1996.

RODRIGUES, R. S. Caracterização de extrato de soja obtido de grãos, farinha integral e isolado proteico visando à formulação e avaliação biológica (em coelhos) de bebida funcional à base de extrato de soja e polpa de pêssegos. 2003. 177f. Tese (Doutorado em Tecnologia de Alimentos) - Faculdade de Engenharia de Alimentos, Universidade Estadual de Campinas, Campinas, SP.

SILVA, N.; JUNQUEIRA, V. C. A. et al. Manual de métodos de análise microbiológica de alimentos. 3. ed. São Paulo: Varela, 2007.

SILVA, M. S. et al. Composição química e valor proteico do resíduo de soja em relação ao grão de soja. Ciênc. Tecnol. Aliment., Campinas, p. 571-576, jul.-set. 2006.

SILVA, M. R.; SILVA, M. A. A. P. Fatores antinutricionais: inibidores de proteases e lectinas. Revista de Nutrição, v. 13, n. 1, p. 3-9, 2000. 
VIEIRA, R. F.; LOPES, J. D. S. Produção de brotos comestíveis: feijão moyashi, alfafa, trevo, rabanete e brócolis. Viçosa: CPT, 2001.

WILEY, R. C. Minimally processed refrigerated fruits and vegetables. New York: Chapman \& Hall, 1994.

YOKOMIZO, G. K.; DUARTE, J. B.; VELLO, N. A. Correlações fenotípicas entre tamanho de grãos e outros caracteres em topocruzamentos de soja tipo alimento com tipo grão. Pesquisa Agropecuária Brasileira, Brasília, v. 35, n. 11, p. 2235-2241, 2000. 
